\title{
BMJ
}

\section{Perinatal mortality and severe morbidity in low and high risk term pregnancies in the Netherlands: prospective cohort study}

\author{
Annemieke C C Evers, PhD student, resident in gynaecology, ${ }^{1}$ Hens A A Brouwers, neonatologist, ${ }^{2}$ Chantal W \\ P M Hukkelhoven, epidemiologist, ${ }^{3}$ Peter G J Nikkels, pathologist, ${ }^{4}$ Janine Boon, gynaecologist, ${ }^{5}$ Anneke van \\ Egmond-Linden, gynaecologist, ${ }^{6}$ Jacqueline Hillegersberg, paediatrician, ${ }^{7}$ Yvette S Snuif, gynaecologist, ${ }^{8}$ \\ Sietske Sterken-Hooisma, midwife secondary care, ${ }^{9}$ Hein W Bruinse, professor of obstetrics, ${ }^{1}$ Anneke Kwee, \\ gynaecologist ${ }^{1}$
}

${ }^{1}$ Department of Obstetrics, University Medical Center Utrecht, 3584 EA Utrecht, Netherlands

${ }^{2}$ Department of Neonatology, University Medical Center Utrecht

${ }^{3}$ Netherlands Perinatal Registry, Utrecht

${ }^{4}$ Department of Pathology, University Medical Center Utrecht

${ }^{5}$ Department of Obstetrics and Gynaecology,

Diakonessenhospital, Utrecht

${ }^{6}$ Department of Obstetrics and Gynaecology, Zuwe Hofpoort

Hospital, Woerden, Netherlands

${ }^{7}$ Department of Pediatrics, St

Antonius Hospital, Nieuwegein, Netherlands

${ }^{8}$ Department of Obstetrics and Gynaecology, Admiraal de Ruyte Hospital, Goes, Netherlands

${ }^{9}$ Department of Obstetrics and Gynaecology, Meander Medical Center, Amersfoort, Netherlands Correspondence to: A C C Evers a.evers@umcutrecht.nl

Cite this as: BMJ 2010;341:c5639 doi:10.1136/bmi.c5639

\section{ABSTRACT}

Objective To compare incidences of perinatal mortality and severe perinatal morbidity between low risk term pregnancies supervised in primary care by a midwife and high risk pregnancies supervised in secondary care by an obstetrician.

Design Prospective cohort study using aggregated data from a national perinatal register.

Setting Catchment area of the neonatal intensive care unit (NICU) of the University Medical Center in Utrecht, a region in the centre of the Netherlands covering $13 \%$ of the Dutch population.

Participants Pregnant women at 37 weeks' gestation or later with a singleton or twin pregnancy without congenital malformations.

Main outcome measures Perinatal death (antepartum, intrapartum, and neonatal) or admission to a level 3 NICU. Results During the study period 37735 normally formed infants were delivered at 37 weeks' gestation or later. Sixty antepartum stillbirths (1.59 (95\% confidence interval 1.19 to 1.99$)$ per 1000 babies delivered), 22 intrapartum stillbirths (0.58 (0.34 to 0.83) per 1000 babies delivered), and $210 \mathrm{NICU}$ admissions (5.58 (4.83 to 6.33) per 1000 live births) occurred, of which 17 neonates died ( 0.45 ( 0.24 to 0.67 ) per 1000 live births). The overall perinatal death rate was 2.62 (2.11 to 3.14) per 1000 babies delivered and was significantly higher for nulliparous women compared with multiparous women (relative risk $1.65,95 \%$ confidence interval 1.11 to 2.45 ). Infants of pregnant women at low risk whose labour started in primary care under the supervision of a midwife had a significant higher risk of delivery related perinatal death than did infants of pregnant women at high risk whose labour started in secondary care under the supervision of an obstetrician (relative risk 2.33, 1.12 to 4.83). NICU admission rates did not differ between pregnancies supervised by a midwife and those supervised by an obstetrician. Infants of women who were referred by a midwife to an obstetrician during labour had a 3.66 times higher risk of delivery related perinatal death than did infants of women who started labour supervised by an obstetrician (relative risk $3.66,1.58$ to 8.46 ) and a 2.5-fold higher risk of NICU admission (2.51, 1.87 to 3.37). Conclusions Infants of pregnant women at low risk whose labour started in primary care under the supervision of a midwife in the Netherlands had a higher risk of delivery related perinatal death and the same risk of admission to the NICU compared with infants of pregnant women at high risk whose labour started in secondary care under the supervision of an obstetrician. An important limitation of the study is that aggregated data of a large birth registry database were used and adjustment for confounders and clustering was not possible. However, the findings are unexpected and the obstetric care system of the Netherlands needs further evaluation.

\section{INTRODUCTION}

Perinatal mortality is an important indicator of the quality of obstetric care. The Peristat I and II studies, based on data from 1999 and 2004, showed that the Netherlands has almost the highest perinatal mortality (11.4 and 10.0 per thousand) in Europe ${ }^{1-5}$ Several factors are mentioned as possible explanations for this high mortality, such as differences in registration and maternal characteristics of the Dutch childbearing population, restricted management of premature babies, and the absence of standard screening for congenital anomalies. The numbers of older mothers, multiple pregnancies, and mothers belonging to an ethnic minority are relatively high in the Netherlands. ${ }^{56}$ However, this can only partly explain the high perinatal mortality. ${ }^{7}$ Whether the Dutch obstetric care system contributes to this relatively high mortality remains unclear. ${ }^{8}$

The Dutch system is different from all other obstetric care systems in Europe and is characterised by a well defined distribution between primary and secondary care. A distinction is made between women with a low risk of pathology and those with a higher risk. Independent midwives in primary care provide care only to 
women at low risk. Early in pregnancy, healthy women enter into the system at the primary care level. If pregnancy, childbirth, and the postpartum period are uncomplicated, the woman remains under the care of the midwife in primary care. The woman has the choice of a home or a hospital delivery, both under the supervision of her own midwife. If complications occur or risk factors arise during pregnancy or labour or in the postpartum period, the woman is referred to an obstetrician in secondary care. In some pregnancies, risk factors based on medical or obstetric history are already present early in pregnancy. In these cases, obstetric care starts directly at the secondary care level by the obstetrician. The indications for referral from primary to secondary care have been agreed by the professionals involved and are laid out in the "obstetric indication list."9

In 2007 a prospective cohort study of severe morbidity and mortality of term fetuses or neonates, called ATNICID (Admission of Term Neonates to Intensive Care or Intrauterine Death), started in the centre of the Netherlands. This study had two aims. The first aim was to improve the quality of obstetric care by organising audits of all cases of perinatal mortality and severe morbidity of term infants (at least 37 weeks) without severe congenital malformations, chromosomal abnormalities, or metabolic diseases. The second aim was to gain insight into perinatal mortality and severe morbidity in relation to the Dutch obstetric care system. We chose to limit the analysis to normally formed term infants because this is a well defined cohort in which perinatal mortality is higher than in most European countries (Peristat $\mathrm{II}^{10}$ ) and both midwives and obstetricians are involved in the care of these patients, depending on the risk factors present. In this paper we report on the perinatal death rate and severe perinatal morbidity of normally formed term infants from pregnancies that were supervised by midwives in primary care as no risk factors were initially present and from pregnancies that were supervised by an obstetrician in secondary care.

\section{METHODS}

We did a prospective cohort study, including cases in a prospective manner. We estimated the population at risk from retrospective registry data.

\section{Study population}

Between 1 January 2007 and 31 December 2008 we prospectively collected data on all antepartum stillbirths, intrapartum stillbirths, neonatal deaths, and admissions to a level 3 neonatal intensive care unit (NICU) of term infants within the first seven days of life in the research area. We defined the research area as the catchment area of the NICU of the University Medical Center Utrecht in the centre of the Netherlands. This unit is one of 10 Dutch level 3 NICUs, which care for $13 \%$ of all neonates with need for intensive care in the Netherlands. All hospitals (one university hospital, seven non-university teaching hospitals, and four general hospitals) and midwife practices $(\mathrm{n}=56)$ that refer neonates to this NICU participated in the study. This part of the Netherlands is a geographically distinct area with approximately 21000 deliveries a year.

\section{Obstetric and neonatal variables}

We systematically recorded obstetric and neonatal variables for each mother-infant pair. The researcher used the original medical records to collect information about the pregnancy, the course of delivery, and the state of the newborn at birth immediately after admission to the NICU. Neonatal data were recorded at the time of death or discharge of the neonate from the NICU.

Gestational age was determined on the basis of the last menstrual period in combination with early ultrasonography. We defined nulliparous women as women who had never given birth to a fetus of more than 16 weeks' gestation and multiparous women as those with one or more deliveries after 16 weeks' gestation. We defined an elective caesarean section as one for which no intention to deliver vaginally existed. According to the Dutch national obstetric guidelines, women at low risk can start labour under the supervision of a midwife in primary care (with a choice between birth at home or in hospital). Women at high risk start labour under the supervision of an obstetrician in hospital. We categorised obstetric care during labour into five overlapping groups: start of labour in primary care, start of labour in secondary care, delivery in primary care, referral from primary care to secondary care during labour, and delivery in secondary care.

An expert panel audited all cases. The panel consisted of eight members from different professions: a midwife working in primary care, a midwife working in secondary care, obstetricians, paediatricians, and a pathologist. They used clear definitions to classify deaths in a systematic way as antepartum, intrapartum, neonatal, or delivery related. They also decided which level of care the woman had received and determined the reason for admission of the neonate to the NICU.

\section{Definitions}

We defined antepartum stillbirth as a death of a fetus after 37 weeks' gestation before the onset of labour and intrapartum stillbirth as a stillbirth in which intrauterine fetal death occurred after the onset of labour but before birth. We defined delivery related neonatal death as the combination of intrapartum stillbirth and neonatal death caused by complications that occurred during labour (asphyxia or intrauterine infection). We did not include late neonatal deaths of infants after seven days of life in our perinatal death rates.

\section{Data from birth registry}

Data collected on perinatal mortality and admission to the NICU were related to parity and level of care during pregnancy and delivery. Data on the total number of term births, parity, and place of delivery came retrospectively from the Netherlands perinatal registry and 
were based on postal codes (catchment area of the NICU) from 2007-8. About 95\% of primary care data and $99 \%$ of secondary care data on pregnancy and delivery are entered in this database. Data on multiple pregnancies and elective caesarean sections also came from the Netherlands perinatal registry. We used these data to calculate perinatal death and admission rates. As intrapartum death and delivery related neonatal death are very uncommon after an elective caesarean delivery in the event of a term fetus without congenital anomalies, we excluded elective caesarean sections from the denominator for intrapartum and delivery related neonatal death.

\section{Statistical analysis}

We calculated incidences with the total number of term neonates born in the research area during the study period as the denominator. For antepartum death, the denominator included all fetuses alive at 37 weeks. For intrapartum death, we excluded antepartum deaths from the denominator; for NICU admission, the denominator included live births only.

We used SPSS 12.0 for Windows and Confidence Interval Analysis for statistical analysis. We calculated crude relative risks with 95\% confidence intervals. We defined the group of women who started labour in secondary care as the reference group. We did a sensitivity analysis to investigate the robustness of our findings because of possible under-registration in primary care (approximately 5\%). To be sure to capture all possible under-registration, we increased the denominator of the low risk group artificially by $10 \%$. Because we included twins in our study and could only analyse them as separate infants rather than clusters (as information at the level of the individual mother was not available), we also did a sensitivity analysis without twins.

We did not include neonates referred from other regions to our NICU because of capacity problems in their own region during the study period in this study cohort. However, we did include neonates born in our research area who were admitted to another NICU because of capacity problems in our region. To get insight into the generalisability of our study results, we extracted data on the following variables from the database: parity $(0$ or $\geq 1)$, age $(\geq 35$ or $<35)$, ethnicity (Western or non-Western), and socioeconomic class (five categories) for the region of the study population and for the remaining part of the Netherlands.

To guarantee anonymity for the participants, we collected data without knowledge of the personal characteristics (name, date of birth, address) of the woman, the obstetric caregiver, or the hospital. Therefore, we could not link our perinatal death and NICU cases to the national database, making a multivariate analysis to adjust for confounders and clustering of patients in hospitals and midwives' practices impossible. However, we compared the prevalence of several risk factors between women at low risk in primary care and women at high risk in secondary care, by using data from the national perinatal registry. We used $\chi^{2}$ tests to see if significant differences existed. We considered a two sided $\mathrm{P}$ value of $<0.05$ to be significant.

\section{RESULTS}

During the study period, 37735 normally formed infants were born at term in the catchment area of our NICU: 16672 (44.2\%) infants of nulliparous women (including $143(0.9 \%)$ twin pregnancies) and 21063 $(55.8 \%)$ infants of multiparous women (including 226 $(1.1 \%)$ twin pregnancies). Data on $91(0.2 \%)$ infants were missing; we excluded these from further analysis. The figure shows that 18686 (49.5\%) infants were born to women who started labour in primary care as low risk, of whom $5492(29.4 \%)$ were referred to secondary care during labour; 13194 (35.0\%) infants were born under the supervision of a midwife in primary care, and $24450(64.8 \%)$ infants were born under the supervision of a gynaecologist. Overall, an elective caesarean section was done in 2163 (5.7\%) deliveries: 765 were nulliparous women (including 37 twin pregnancies), and 1398 were multiparous women (including 44 twin pregnancies).

In total, 60 antepartum deaths (1.59 (95\% confidence interval 1.19 to 1.99$)$ per 1000 babies delivered), 22 intrapartum deaths $(0.58$ ( 0.34 to 0.83$)$ per 1000 babies delivered), and 210 admissions to the NICU (5.58 (4.83 to 6.33$)$ per 1000 live births delivered) occurred, of which 17 (0.45 (0.24 to 0.67 ) per 1000 live births) neonates died (table 1). The overall perinatal death rate was 2.62 (2.11 to 3.14 ) per 1000 babies delivered, and this death rate was significantly higher for nulliparous women than for multiparous women (relative risk 1.65, $95 \%$ confidence interval 1.11 to 2.45 ). Of the 60 antepartum stillbirths, 37 occurred in primary care and 23 in secondary care. We could not calculate the incidence

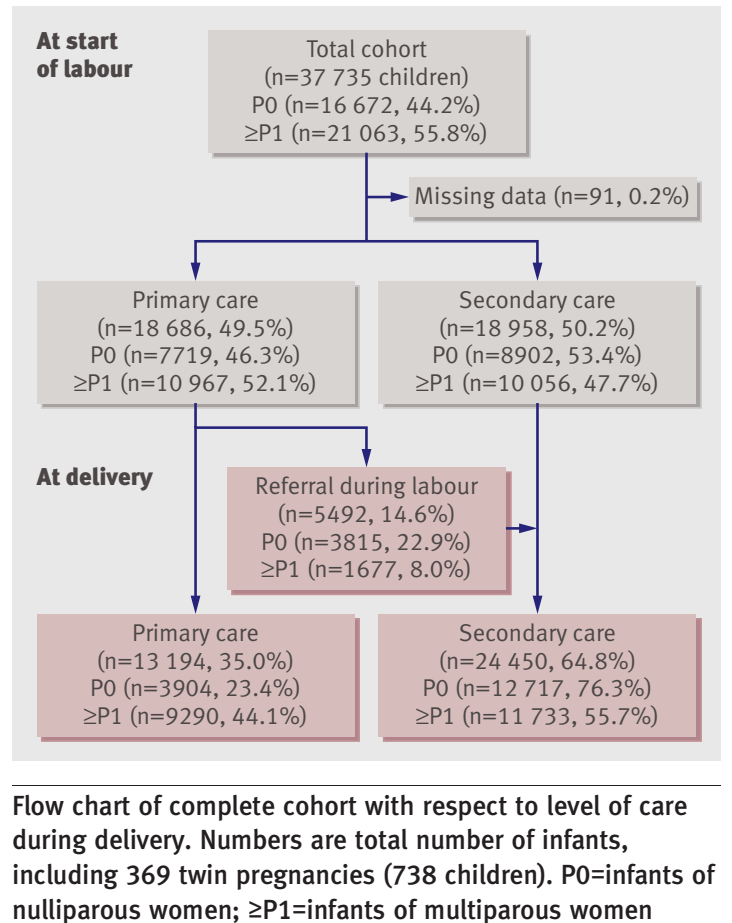




\begin{tabular}{|c|c|c|c|c|}
\hline Outcome & Total cohort & No of deaths & $\begin{array}{l}\text { Incidence } / 1000 \\
(95 \% \mathrm{Cl})\end{array}$ & $\begin{array}{l}\text { Relative risk } \\
(95 \% \mathrm{Cl})\end{array}$ \\
\hline Antepartum stillbirth & 37735 & 60 & 1.59 (1.19 to 1.99$)$ & \\
\hline Nulliparous & 16672 & 35 & 2.10 (1.40 to 2.79$)$ & 1.77 (1.06 to 2.95$)$ \\
\hline Multiparous & 21063 & 25 & $1.19(0.72$ to 1.65$)$ & Reference \\
\hline Intrapartum stillbirth & 37675 & 22 & $0.58(0.34$ to 0.83$)$ & \\
\hline Nulliparous & 16637 & 14 & 0.84 (0.40 to 1.28$)$ & 2.21 (0.93 to 5.27$)$ \\
\hline Multiparous & 21038 & 8 & $0.38(0.12$ to 0.64$)$ & Reference \\
\hline Neonatal death & 37653 & 17 & $0.45(0.24$ to 0.67$)$ & \\
\hline Nulliparous & 16623 & 7 & $0.42(0.11$ to 0.73$)$ & 0.89 (0.34 to 2.33$)$ \\
\hline Multiparous & 21030 & 10 & $0.48(0.18$ to 0.77$)$ & Reference \\
\hline Perinatal death & 37735 & 99 & 2.62 (2.11 to 3.14$)$ & \\
\hline Nulliparous & 16672 & 56 & $3.36(2.48$ to 4.24$)$ & 1.65 (1.11 to 2.45$)$ \\
\hline Multiparous & 21063 & 43 & 2.04 (1.43 to 2.65$)$ & Reference \\
\hline
\end{tabular}

of antepartum stillbirth at either level of care because we did not have the denominator, as the perinatal registry contains only the level of care at the start of labour.

Twenty-two intrapartum stillbirths and 14 delivery related neonatal deaths occurred (tables 2 and 3). Infants of pregnant women at low risk had a significantly higher risk of delivery related perinatal death (relative risk 2.33, 1.12 to 4.83) (table 3), compared with infants of women at high risk whose labour started in secondary care under the supervision of an obstetrician. Infants of women who were referred to secondary care during labour had a 3.66 times higher risk of delivery related perinatal death than did infants of women who started labour in secondary care (relative risk 3.66, 1.58 to 8.46 ) (table 3).

Two hundred and thirty-eight neonates were admitted to the study NICU; 30 neonates were born in another region and were therefore excluded, and two neonates born in our region and admitted to other NICUs were included retrospectively. In total, we included 210 neonates, resulting in an overall incidence of admission to NICU of 5.58 (4.83 to 6.33) per 1000 live births. We did not exclude women who delivered by elective caesarean section from denominator numbers. Nulliparous women had a significantly higher risk than did multiparous women 8.03 (6.67 to 9.38$) v 3.67$ (2.85 to 4.49 ) per 1000 live births; relative risk $2.19,1.65$ to 2.89 ) of their child being admitted to the NICU. Half of the women $(51 \%, \mathrm{n}=107)$ started labour in primary care. Of these, $70 \%(\mathrm{n}=75)$ were referred to secondary care during labour. In the end, $85 \%(\mathrm{n}=179)$ delivered in secondary care. The incidence of admissions to the NICU was 2.43 per 1000 term births in primary care, 13.7 per 1000 term births if referral to secondary care during labour occurred, and 5.45 per 1000 term births managed exclusively in secondary care (table 4). Reasons for admission to the NICU were asphyxia $(\mathrm{n}=101,48 \%)$, infection (32, $15 \%)$, respiratory distress $(25,12 \%)$, meconium aspiration syndrome $(10,5 \%)$, cerebral morbidity $(16,8 \%)$, seizures $(5,2 \%)$, and other reasons $(21,10 \%)$. In total, $17(8 \%)$ neonates died in the neonatal period, $71 \%$ $(n=12)$ because of asphyxia and $29 \%(n=5)$ because of an infection. Fourteen cases were classified as directly related to circumstances during labour. In two of the three non-delivery related deaths, asphyxia occurred before the start of labour. In the remaining case, the reason for admission to the NICU was a neonatal infection (Enterobacter meningitis).

Of the 26 delivery related deaths for which labour started in primary care, labour started at home in 17 $(65 \%)$ cases and in the hospital in nine $(35 \%)$ cases. For

Table 2| Intrapartum death rate among term infants without congenital malformations, comparing infants of women whose labour started in primary care and those referred during labour with infants of women who started labour in secondary care

\begin{tabular}{|c|c|c|c|c|c|}
\hline Variables & Total * & $\begin{array}{l}\text { Intrapartum } \\
\text { stillbirth† }\end{array}$ & $\begin{array}{l}\text { Incidence } / 1000 \\
(95 \% \mathrm{Cl})\end{array}$ & $\begin{array}{l}\text { Relative risk } \\
(95 \% \mathrm{Cl})\end{array}$ & $\begin{array}{c}\text { Risk difference } / 1000 \\
(95 \% \mathrm{Cl})\end{array}$ \\
\hline Start of labour in primary care & 18686 & 18 & $0.96(0.52$ to 1.41$)$ & $4.03(1.36$ to 11.9$)$ & $0.72(0.22$ to 1.23$)$ \\
\hline Nulliparous & 7719 & 10 & 1.30 (0.49 to 2.10$)$ & $2.62(0.82$ to 8.37$)$ & $0.80(0.14$ to 1.74$)$ \\
\hline Multiparous & 10967 & 8 & $0.73(0.22$ to 1.23$)$ & & $0.73(0.22$ to 1.23$)$ \\
\hline Start of labour in secondary care & 16739 & 4 & 0.24 (0.01 to 0.47$)$ & Reference & \\
\hline Nulliparous & 8104 & 4 & 0.49 (0.01 to 0.98$)$ & & \\
\hline Multiparous & 8635 & 0 & 0 & & \\
\hline Referral to secondary care during labour & 5492 & 6 & $1.09(0.22$ to 1.97$)$ & $4.57(1.29$ to 16.2$)$ & $0.85(0.05$ to 1.76$)$ \\
\hline Nulliparous & 3815 & 4 & 1.05 (0.31 to 2.62$)$ & $2.12(0.53$ to 8.49$)$ & $0.56(0.58$ to 1.69$)$ \\
\hline Multiparous & 1677 & 2 & 1.19 (0.18 to 4.33$)$ & & $1.19(0.18$ to 4.33$)$ \\
\hline Delivery in primary care & 13194 & 12 & 0.91 (0.40 to 1.42$)$ & $3.81(1.23$ to 11.8$)$ & $0.67(0.11$ to 1.24$)$ \\
\hline Nulliparous & 3904 & 6 & $1.54(0.55$ to 3.36$)$ & $3.11(0.89$ to 11.0$)$ & $1.04(0.28$ to 2.36$)$ \\
\hline Multiparous & 9290 & 6 & 0.65 (0.13 to 1.16$)$ & & 0.65 (0.13 to 1.16$)$ \\
\hline Delivery in secondary care & 22231 & 10 & $0.45(0.17$ to 0.73$)$ & Not calculated & Not calculated \\
\hline Nulliparous & 11919 & 8 & 0.67 (0.21 to 1.14$)$ & & \\
\hline Multiparous & 10312 & 2 & $0.19(0.07$ to 0.46$)$ & & \\
\hline Missing & 87 & & & & \\
\hline Total & 35512 & 22 & $0.62(0.36$ to 0.88$)$ & & \\
\hline
\end{tabular}


Table 3|Delivery related death rate among term infants without congenital malformations, comparing infants of women whose labour started in primary care and those referred during labour with infants of women who started labour in secondary care

\begin{tabular}{|c|c|c|c|c|c|}
\hline Variables & Total* & $\begin{array}{l}\text { Delivery related } \\
\text { perinatal death }\end{array}$ & $\begin{array}{l}\text { Incidence/1000 } \\
(95 \% \mathrm{Cl})\end{array}$ & $\begin{array}{l}\text { Relative risk } \\
(95 \% \mathrm{Cl})\end{array}$ & $\begin{array}{c}\text { Risk difference } / 1000 \\
(95 \% \mathrm{Cl})\end{array}$ \\
\hline Start of labour in primary care & 18686 & 26 & 1.39 (0.86 to 1.93$)$ & $2.33(1.12$ to 4.83$)$ & 0.79 (0.14 to 1.44$)$ \\
\hline Nulliparous & 7719 & 13 & $1.68(0.77$ to 2.60$)$ & 2.27 (0.87 to 5.98$)$ & 0.94 (0.15 to 2.03$)$ \\
\hline Multiparous & 10967 & 13 & $1.19(0.54$ to 1.83$)$ & $2.56(0.84$ to 7.85$)$ & $0.72(0.07$ to 1.51$)$ \\
\hline Start of labour in secondary care & 16739 & 10 & $0.60(0.23$ to 0.97$)$ & Reference & \\
\hline Nulliparous & 8104 & 6 & $0.74(0.15$ to 1.33$)$ & & \\
\hline Multiparous & 8635 & 4 & $0.46(0.01$ to 0.92$)$ & & \\
\hline Referral to secondary care during labour & 5492 & 12 & 2.18 (0.95 to 3.42$)$ & $3.66(1.58$ to 8.46$)$ & 1.59 (0.30 to 2.88$)$ \\
\hline Nulliparous & 3815 & 7 & $1.83(0.79$ to 3.72$)$ & $2.48(0.83$ to 7.37$)$ & 1.09 (0.39 to 2.58$)$ \\
\hline Multiparous & 1677 & 5 & 2.98 (0.92 to 6.90) & 6.44 (1.73 to 23.9$)$ & $2.52(0.13$ to 5.17$)$ \\
\hline Delivery in primary care & 13194 & 14 & $1.06(0.51$ to 1.62$)$ & $1.78(0.79$ to 4.00$)$ & $0.46(0.20$ to 1.13$)$ \\
\hline Nulliparous & 3904 & 6 & $1.54(0.55$ to 3.36$)$ & $2.08(0.67$ to 6.43$)$ & $0.80(0.57$ to 2.16$)$ \\
\hline Multiparous & 9290 & 8 & $0.86(0.27$ to 1.46$)$ & $1.86(0.56$ to 6.17$)$ & $0.40(0.35$ to 1.15$)$ \\
\hline Delivery in secondary care & 22231 & 22 & 0.99 (0.58 to 1.40$)$ & Not calculated & Not calculated \\
\hline Nulliparous & 11919 & 13 & 1.09 (0.50 to 1.68$)$ & & \\
\hline Multiparous & 10312 & 9 & $0.87(0.30$ to 1.44$)$ & & \\
\hline Missing & 87 & & & & \\
\hline Total & 35512 & 36 & $1.01(0.68$ to 1.34$)$ & & \\
\hline
\end{tabular}

the 107 admissions to the NICU, the equivalent numbers were $62(58 \%)$ and $42(42 \%)$.

The sensitivity analysis showed our findings to be robust when we increased the denominator of the low risk group by $10 \%$ (web appendix A) and when we excluded multiple gestations (web appendix B). Because we could not adjust for confounders, we compared the prevalence of several risk factors between women at low risk in primary care and women at high risk in secondary care, using data from the national perinatal registry. Analysis of the variables (parity, age, socioeconomic class, ethnicity, multiple pregnancy) showed that nulliparity, age 35 or over, non-Western ethnicity, low socioeconomic class, and multiple pregnancies were more prevalent among women at high risk in secondary care. We hypothesise that if we could have adjusted for these risk factors, the effect would have been even larger as the risk factors were more prevalent among women at high risk (web appendix $\mathrm{C}$ ).

\section{DISCUSSION}

The main finding of this study is that the Dutch obstetric system that is based on risk selection and obstetric care at two levels may not be as effective as was once thought. The Dutch obstetric system itself possibly contributes to the high perinatal mortality compared with most European countries. We found that delivery related perinatal death was significantly higher among low risk pregnancies in midwife supervised primary care than among high risk pregnancies in obstetrician supervised secondary care. This difference was even greater among the cases that were referred from primary to secondary care during labour. Unfortunately, we were unable to adjust for confounding variables because we used aggregated data from a large birth registry database. However, the results are unlikely to have been overestimated, because risk factors such as low socioeconomic status, higher age, or non-Western ethnicity were more prevalent among the women at high risk.

As we explained in the results section, we could not compare antepartum fetal death at term between the two levels of care. However, 37 cases of antepartum stillbirths occurred in primary care and 23 cases in secondary care. At the start of labour, $49.5 \%$ of all women were supervised by a midwife and $50.2 \%$ by an obstetrician, so the incidence of antepartum stillbirth probably did not differ between the low risk group and the high risk group. With respect to severe morbidity in normal term infants (that is, admission to a level 3 neonatal intensive care unit) we found no difference between the low risk and high risk pregnancies. Five per 1000 babies were admitted in both groups, of which $8 \%$ died. The perinatal death rate after 37 weeks of gestation in normally formed term infants was 2.62 per 1000 babies. This is in accordance with the results of the Peristat II study comparing perinatal death rates between different countries in Europe. ${ }^{10}$ This study reported a perinatal death rate of 3.2 per 1000 term babies in the Netherlands, including infants with congenital anomalies. Congenital abnormalities are assumed to contribute at least 0.4 per 1000 babies to the perinatal death rate, so the high perinatal mortality in the centre of the Netherlands seen in our study is similar to that in the Peristat II study. ${ }^{10}$

\section{Strengths and weaknesses of study}

A limitation of our study is that we used aggregated data from a large birth registry database to determine denominator numbers. Under-reporting could have influenced these numbers, as $95 \%$ of primary care data and $99 \%$ of secondary care data are entered in 
Table 4 | Incidence of NICU admissions of term neonates, comparing infants of women whose labour started in primary care and those referred during labour with infants of women who started labour in secondary care

\begin{tabular}{|c|c|c|c|c|c|}
\hline Variables & Total* & $\begin{array}{c}\text { NICU } \\
\text { admissions }\end{array}$ & $\begin{array}{l}\text { Incidence } / 1000 \\
(95 \% \mathrm{Cl})\end{array}$ & $\begin{array}{l}\text { Relative risk } \\
(95 \% \mathrm{Cl})\end{array}$ & $\begin{array}{l}\text { Risk difference } / 1000 \\
(95 \% \mathrm{Cl})\end{array}$ \\
\hline Start of labour in primary care & 18668 & 107 & $5.73(4.65$ to 6.81$)$ & $1.05(0.80$ to 1.38$)$ & $0.28(-1.23$ to 1.79$)$ \\
\hline Nulliparous & 7709 & 73 & $9.47(7.31$ to 11.6$)$ & 1.40 (1.00 to 1.97$)$ & $2.70(-0.06$ to 5.45$)$ \\
\hline Multiparous & 10959 & 34 & $3.10(2.06$ to 4.14$)$ & $0.72(0.46$ to 1.13$)$ & $-1.18(-2.83$ to 0.47$)$ \\
\hline Start of labour in secondary care & 18894 & 103 & 5.45 (4.40 to 6.50$)$ & Reference & \\
\hline Nulliparous & 8863 & 60 & 6.77 (5.06 to 8.48$)$ & & \\
\hline Multiparous & 10031 & 43 & $4.29(3.01$ to 5.57$)$ & & \\
\hline $\begin{array}{l}\text { Referral to secondary care during } \\
\text { labour }\end{array}$ & 5486 & 75 & 13.7 (10.6 to 16.7$)$ & 2.51 (1.87 to 3.37$)$ & $8.22(4.97$ to 11.5$)$ \\
\hline Nulliparous & 3811 & 58 & $15.2(11.5$ to 19.6$)$ & 2.25 (1.57 to 3.22$)$ & 8.45 (4.20 to 12.7$)$ \\
\hline Multiparous & 1675 & 17 & 10.1 (5.92 to 16.2$)$ & 2.37 (1.35 to 4.14$)$ & $5.86(0.90$ to 10.8$)$ \\
\hline Delivery in primary care & 13182 & 32 & $2.43(1.59$ to 3.27$)$ & $0.45(0.30$ to 0.66$)$ & $-3.02(-4.37$ to -1.68$)$ \\
\hline Nulliparous & 3898 & 14 & $3.59(2.01$ to 6.04$)$ & $0.53(0.30$ to 0.95$)$ & $-3.18(-5.72$ to -0.64$)$ \\
\hline Multiparous & 9284 & 18 & 1.94 (1.04 to 2.83$)$ & 0.45 (0.26 to 0.78$)$ & $-2.35(-3.91$ to -0.79$)$ \\
\hline Delivery in secondary care & 24380 & 178 & 7.30 (6.23 to 8.37$)$ & Not calculated & Not calculated \\
\hline Nulliparous & 12674 & 118 & 9.31 (7.64 to 11.0$)$ & & \\
\hline Multiparous & 11706 & 60 & 5.13 (3.83 to 6.42$)$ & & \\
\hline Missing & 91 & & & & \\
\hline Total & 37653 & 210 & $5.58(4.83$ to 6.33$)$ & & \\
\hline
\end{tabular}

the national perinatal registry database. However, the results remained similar after a conservative sensitivity analysis. Furthermore, the overall perinatal mortality was comparable to the rates described in the Peristat II study. ${ }^{10}$ Another limitation is that we could not adjust for risk factors because we used aggregated data and cases could not be linked to the database. However, we showed that known risk factors for adverse perinatal outcome (age 35 or over, low socioeconomic class, and non-Western ethnicity) are over-represented in secondary care. If we could adjust for these factors, we would expect an even greater difference in perinatal death rates between the two levels of care. Analysis of some risk factors showed that women with a higher socioeconomic class, Western ethnicity, and age above 35 were slightly over-represented in the study area compared with the rest of the Netherlands. However, the perinatal mortality for singletons in the province of Utrecht was virtually the same as that in the rest of the Netherlands -10.0 versus 10.2 per 1000 babies.

A major strength of our study is that a multidisciplinary team consisting of obstetricians, midwives, neonatologists, and a pathologist classified all deaths. They used clear definitions to classify deaths as antepartum, intrapartum, neonatal, and delivery related in a systematic way. Under-reporting and misclassification of deaths and admissions to the NICU are therefore most unlikely. This is a major strength of our study compared with other studies that have used large databases.

\section{Findings in relation to other studies}

To our knowledge, this is the only study in the Netherlands to show a higher risk of delivery related perinatal mortality among women with the intention to deliver in primary care compared with women delivered in secondary care. Comparing intended home and hospital births in a cohort of 529688 low risk pregnancies in primary care in the Netherlands, de Jonge et al recently found low rates of perinatal mortality (intrapartum and neonatal death before 7 days) and admission to the NICU. ${ }^{11}$ They concluded that an intended home birth does not increase risks compared with an intended hospital birth in this population. However, women who were referred during labour were not analysed separately in this study, and no comparison was made with high risk pregnancies in secondary care. The incidences of delivery related perinatal mortality and NICU admissions were lower than the rates we found- 0.5 versus 1.04 per 1000 babies delivered and 2.0 versus 5.6 per 1000 . A possible explanation could be the retrospective use of a large database, in which data can be missing or filled in incorrectly. Misclassification of intrapartum deaths could be one of these factors. Absent fetal heart beat discovered during labour, after which the woman was referred to secondary care, could have been classified as antepartum deaths, whereas we classified these according to the course of labour into antepartum or intrapartum death.

Ravelli et al reported an overall perinatal mortality for normal term infants of 2.8 per 1000 babies delivered, almost the same as in our study. ${ }^{12}$ However, they found a perinatal mortality in a population at low risk of 1.3 per 1000 (0.4 per 1000 for home births, 0.9 per 1000 in outpatient clinics (midwife led), and 2.4 per 1000 for intrapartum referral) and a higher perinatal mortality rate of 4.5 per 1000 in a high risk population. ${ }^{12}$ This discordance between their study and ours may be explained by the fact that when antepartum stillbirths occur in primary care they are 


\section{WHAT IS ALREADY KNOWN ON THIS TOPIC}

Despite the high level of medical care in the Netherlands, the perinatal death rate is one of the highest in Europe

The obstetric care system in the Netherlands is characterised by midwife led care for pregnant women at low risk and obstetrician led care for those at high risk

Home birth is still practised in the low risk group, and $22 \%$ actually deliver at home

\section{WHAT THIS STUDY ADDS}

Infants of low risk pregnant women who started labour in primary care had a higher risk of delivery related perinatal death than did infants of high risk pregnant women who started labour in secondary care

The obstetric care system in the Netherlands may contribute to the high perinatal mortality

referred to the gynaecologist before labour starts and are then counted in the death rates of secondary care.

Finally, Amelink-Verburg et al evaluated a cohort of more than 280000 women at low risk and found a low perinatal (intrapartum and first day) mortality of 0.5 per 1000 babies. ${ }^{13}$ However, in agreement with our study, they found a relative high mortality in women who where referred during labour on an emergency basis (fetal distress) of 10.7 per 1000 babies delivered. However, only $3.6 \%$ of women who started labour in primary care had to be referred as an emergency.

The authors of these studies all state that the Dutch obstetric care system, based on risk selection and obstetric care at two levels, works well. We challenge this statement, as we found that the perinatal death rate of women at low risk intended to deliver in primary care was higher than that of women at high risk delivering in secondary care. In particular, infants of women who were referred from primary to secondary care during labour had a more than 3.5-fold higher perinatal death rate compared with infants of women who started labour in secondary care. In $200740 \%$ of nulliparous women started labour in primary care, of whom 43\% were referred to secondary care during labour; the equivalent figures for multiparous women were $47 \%$ and $13 \%$.

\section{Meaning of study}

Our in-depth analysis of the perinatal mortality of normal term infants has shown that delivery related deaths are higher in the so-called low risk pregnancies supervised by a midwife in primary care than in the high risk pregnancies supervised by an obstetrician in secondary care. This seriously questions the supposed effectiveness of the Dutch obstetric system that is based on risk selection and obstetric care at two levels. Of major concern is the fact that the highest mortality was among the infants of women who were referred from primary care to secondary care during labour because of an apparent complication. Hypothetically, this high mortality could have several causes. Delay can occur at three moments. Firstly, diagnosis in primary care can be delayed because the midwife is not always present during the first stage of labour and fetal heart beats are often checked only every two to four hours. Secondly, transport can delay treatment in case of an emergency. Finally, a delay can occur because the obstetrician underestimates the problem as the referred woman is a "low risk" patient. In addition, essential information can be lost during the referral. These factors should be subject to further investigation, especially to evaluate whether complications with the potential to lead to perinatal death can better be predicted.

On the other hand, one may wonder whether the obstetric care system in the Netherlands need to be critically revised. Less than $50 \%$ of nulliparous women start labour in primary care, of whom $43 \%$ are referred to secondary care during labour. For multiparous women, the figures are $45 \%$ and $13 \%$. So the number of women who finally deliver in primary care is rather limited. Against the background of the observed perinatal mortality data, a close cooperation or even a fusion between the two levels of care may be the preferred solution. The role of the midwife should not be underestimated and is most likely one of the reasons that the rate of caesarean section is still the lowest in Europe.

\section{Unanswered questions and future research}

The main unanswered question remains whether the high perinatal death rate in the Netherlands compared with the rest of Europe can be lowered within the existing obstetric care system. In our opinion, this implies a critical assessment of the course of events that results in an adverse outcome - an assessment in which all professionals are involved. Such an audit is being arranged on a national basis in the Netherlands. In our ATNICID study, a detailed audit on factors associated with substandard care in cases with an adverse outcome is ongoing. Further research should be directed to different care systems in which midwives and obstetricians work much more closely together.

In summary, the Dutch obstetric care system is based on the assumptions that pregnant women and women in labour can be divided into a low risk group and a high risk group, that the first group of women can be supervised by a midwife (primary care) and the second group by an obstetrician (secondary care), and that women in the primary care group can deliver at home or in hospital with their own midwife. When complications occur or risk factors arise antenatally, during labour, or in the puerperium in primary care, the women is referred to secondary care.

We found that the perinatal death rate of normal term infants was higher in the low risk group than in the high risk group, so the Dutch system of risk selection in relation to perinatal death at term is not as effective as was once thought. This also implies that the high perinatal death rate in the Netherlands compared with other European countries may be caused by the obstetric care system itself, among other factors. A critical evaluation of the obstetric care system in the Netherlands is thus urgently needed.

We thank all midwives and gynaecologists in the study area for their participation in the study, collection of data, and valuable discussions at the audit meetings. We thank the Netherlands perinatal registry for permission to use data. 
Contributors: $A K, H W B$, and $H A A B$ initiated and coordinated the study. ACCE, AK, HWB, HAAB, and PGJN were involved in designing the study protocol. ACCE coordinated logistics, data collection, and quality control of data. AK, CWPMH, and ACCE analysed the data. All authors actively participated in interpreting the results and revising the paper, which was written by ACCE, AK, HWB, and HAAB. AK is the guarantor.

Funding: None

Competing interests: None declared.

Ethical approval: Not needed for this type of study in the Netherlands. Data sharing: Dataset available from corresponding author at a.evers@umcutrecht. Consent was not obtained, but presented data are anonymised and risk of identification is low.

1 Wildman K, Blondel B, Nijhuis J, Defoort P, Bakoula C. European indicators of health care during pregnancy, delivery and the postpartum period. Eur J Obstet Gynecol Reprod Biol 2003;111:S53-65.

2 Buitendijk S, Zeitlin J, Cuttini M, Langhoff-Roos J, Bottu J. Indicators of fetal and infant health outcomes. Eur J Obstet Gynecol Reprod Biol 2003;111(suppl 1):66-77S

3 Buitendijk SE, Nijhuis JG. High perinatal mortality in the Netherlands compared to the rest of Europe. Ned Tijdschr Geneeskd 2004;148:1855-60.

4 Richardus JH, Graafmans WC, Verloove-Vanhorick SP, Mackenbach JP, EuroNatal International Audit Panel, EuroNatal Working Group. Differences in perinatal mortality and suboptimal care between 10 European regions: results of an international audit. BJOG 2003;110:97-105.

5 Mohangoo AD, Buitendijk SE, Hukkelhoven CW, Ravelli AC, Rijninksvan Driel GC, Tamminga P, et al. Higher perinatal mortality in the Netherlands than in other European countries: the Peristat-II study. Ned Tijdschr Geneeskd 2008;152:2718-27.
6 Anthony S, Jacobusse GW, van der Pal-de Bruin KM, Buitendijk S, Zeitlin J, EURO-PERISTAT Working Group on Risk Factors. Do differences in maternal age, parity and multiple births explain variations in fetal and neonatal mortality rates in Europe? Results from the EURO-PERISTAT project. Paediatr Perinat Epidemiol 2009;23:292-300.

7 Achterberg PW. Measuring up to the best? International differences in perinatal mortality. 2005. www.rivm.nl/bibliotheek/rapporten/ 270032001.pdf.

8 Merkus JM. Obstetric care in the Netherlands under assessment again. Ned Tijdschr Geneeskd 2008;152:2707-8.

9 Commissie verloskunde van het CVZ. Verloskundig vademecum 2003. College voor zorgverzekeringen, 2003

10 Zeitlin J, Mohangoo A, Cuttini M, EUROPERISTAT Report Writing Committee, Alexander S, Barros H, et al. The European perinatal health report: comparing the health and care of pregnant women and newborn babies in Europe. J Epidemiol Community Health 2009;63:681-2.

11 De Jonge A, van der Goes BY, Ravelli AC, Amelink-Verburg MP, Mol BW, Nijhuis JG, et al. Perinatal mortality and morbidity in a nationwide cohort of 529688 low-risk planned home and hospital births. BJOG 2009;116:1177-84.

12 Ravelli AC), Eskes M, Tromp M, Van Huis AM, Steegers EAP, Tamminga P, et al. Perinatal mortality in the Netherlands 2000-2006: risk factors and risk selection. Ned Tijdschr Geneesk 2008;152:2728-33.

13 Amelink-Verburg MP, Verloove-Vanhorick SP, Hakkenberg RMA, Veldhuijzen IME, Bennebroek Gravenhorst J, Buitendijk SE. Evaluation of 280000 cases in Dutch midwifery practices: a descriptive study. BJOG 2007;115:570-8.

Accepted: 25 August 2010 